\title{
DOCTOR IN THE DOCK
}

\author{
BIJU C MATHEW ${ }^{1}$, REJI SUSAN DANIEL ${ }^{2}$, JAMAL AL BAHLOOL BORDOM ${ }^{3}$, IAN W CAMPBELL ${ }^{4}$
}

\begin{abstract}
Tobacco smoking is one of the greatest threats to human health. The global epidemic of tobacco killed 100 million in the $20^{\text {th }}$ century, and if not dealt with on a war-footing shall entice and kill another one billion in this century. In the society, physicians play a leading role as ambassadors of promoting issues related to health. They play a vital role in helping patients to stop smoking as they occupy an important position as tobacco control exemplars. Unfortunately, the rate of smoking in the medical profession in some developed countries and newly-developing countries is still high. Considering the staggering cost of smoking in terms of human lives, physicians should not rest until they have successfully kicked the habit. Tobacco-related issues are to be included in the medical school curricula, as medical students can play decisive roles in tobacco-prevention programs.
\end{abstract}

\section{Smoking: A curse on humanity "Smoking is one of the leading causes of statistics"}

\section{- Fletcher Knebel}

Fletcher Knebel, the American author, was absolutely right. Although he was a writer of political fiction, his insight into the statistics of smoking is no fiction, but the chilling truth. And the emerging statistics on the harmful effects of smoking are even more damning. Tobacco is one of the greatest threats to human health. It indeed is great irony that for centuries tobacco was used as a medicine, and later as a recreation drug, until the $19^{\text {th }}$ century, when nicotine was isolated and recognized as a poison. Cigarette smoking is the most common form of tobacco consumption and is frequently described as the leading preventable causes of mortality and morbidity throughout the world.

An estimated 1.2 billion people worldwide are smokers. In developing countries, half of all males smoke. The WHO projects a global smoking population of 1.6 billion by the year $2030 .{ }^{1}$ An estimated 5 million deaths annually can be attributed to tobacco use, and if the current trend continue, it will be causing 10 million deaths each year by 2030 , with $70 \%$ of the deaths occurring in low and middle-income countries .In addition to being a major health problem worldwide, smoking is a formidable barrier to development in the developing countries. The global epidemic of tobacco killed 100 million in the $20^{\text {th }}$ century, and if not dealt with on a war- footing shall entice and kill another one billion in this century. ${ }^{2}$ The damning statistics is a grim reminder of the great threat posed by this manufactured disease primarily from the widespread tobacco consumption mainly in Africa and Asia. To aggravate things further, non-traditional forms of tobacco use such as water pipe smoking (WPS) are being promoted as 'more safe' forms of smoking and more people including youths are experimenting and using WPS regularly. ${ }^{3}$ It must be emphasized that the negative health effects of pipe, cigar, and WPS as well as other forms of tobacco use and moist snuff

1. Assistant Professor, Department of Medical Biochemistry, Faculty of Medicine, El Gabal El Gharby University, Gharyan, Libya.

2. Lecturer, Department of Medical Biochemistry, Faculty of Medicine, El Gabal El Gharby University, Gharyan , Libya

3. Professor, Department of Social and Preventive Medicine \& Dean, Faculty of Medicine, El Gabal El Gharby University, Gharyan, Libya

4. Emeritus Professor of Medicine, Victoria Hospital, Bute Medical School, University of St Andrews, Scotland, United Kingdom. 
deposited between cheek and gum are on par or above that of cigarette smoking. ${ }^{4}$ Recent studies have indicated that after bubbling, particle sizes in water pipe smoke are similar to those measured in cigarette smoke but the volumes inhaled by a water pipe smoker are higher allowing greater deposition in the respiratory tract than with cigarette smoking. ${ }^{5}$ Involuntary inhalation of smoke from tobacco products (passive smoking) has a harmful effect on those exposed to it .Scientific evidence shows that secondhand smoke ( SHS ) or environmental smoke (ETS) can cause disease, disability and death in both adults and children. ${ }^{6}$

The harmful effects of smoking can be bluntly summarized in a single line; "Smoking Kills". It causes 25 diseases and 11 types of cancer .Since the isolation of nicotine in the $19^{\text {th }}$ century, modern analytical techniques have unraveled the contents in the deadly "aerosol cocktail" in cigarette smoke. It contains over 4000 different chemicals, and research has shown that 400 of the 4000 different chemicals are poisonous, and at least 50 are causes of cancer! The destructive effects of smoking harm virtually every organ-system in the body. Cigarette smoking accounts for at least $30 \%$ of all cancer deaths including about $87 \%$ of lung cancer deaths .Smoking has been linked to other health problems, too, including respiratory tract infections, chronic obstructive ulmonary disease (COPD), coronary artery disease, occlusive cerebrovascular disease, aortic aneurysms, peripheral vascular disease, osteoporosis, senile cataracts, peptic ulcer, infertility and sexual dysfunction. ${ }^{4,7}$ Physicians and healthcare professionals can play an active role in patient education and advancing any tobacco control policies. But what if the physician himself is an active smoker! Unfortunately, this is true in many cases and is discussed next.

\section{Physicians vs. cigarettes}

\section{More doctors smoke Camels than any other cigarette!}

This was the slogan used by the American tobacco giant J. Reynolds Tobacco Co, in the mid $20^{\text {th }}$ century to promote their brand of Camel cigarettes. Unbelievable, yet true, in the $20^{\text {th }}$ century, some physicians advertised cigarettes ${ }^{8}$. The doctors' recommendation of Camels lasted until the early 1950's - when the first rumblings about smoking and heath were beginning to surface. The" Herculean blunder" was realized, and corrective measures taken later saw a dramatic drop in the smoking rate among American physicians by the 1980 s. The murky dealings in tobacco business are evident from the hushed remarks that each doctor who smokes is worth hundreds of thousands of dollars to the industry. This is certainly an understatement when it comes to the small group of well rewarded doctors and scientists who routinely do the industry's bidding for them in government inquiries and in the media ${ }^{9}$. When it boils down to the lure of green bucks ethics seem to go up in smoke. Physicians command respect in the society and act as role models in issues related to health, and people look to them for advice and consultation .However, statistics related to smoking among physicians reveal that members of this noble profession often do not seriously address the issue of smoking, or perhaps smoke themselves.

Smith et al in 2007 reviewed all modern literature describing the tobacco smoking habits of contemporary physicians in the past 30 years (1974-2004). ${ }^{10}$ The authors noted that while physicians smoking habits appear to vary from region to region, they are not uniformly low when viewed from an international perspective. Two distinct trends were evident. Firstly, most developed countries have shown a steady decline in physician smoking rates. The lowest overall smoking rates was documented in the United States (2\%), Australia ( $3 \%$ ), New Zealand ( $3 \%$ ), and the United Kingdom (3\%). On the other hand, physicians in some developed countries and newly-developing regions still appear to be smoking at high rates. Multiple investigations from Italy, Japan and France have consistently documented smoking prevalence rates over $25 \%$. The highest smoking prevalence rate was recorded in Greece, where roughly half of all physicians (49\%) reported themselves to be current smokers. Similar high smoking rates were also documented in China ( 45\%), Kuwait (38\%), United Arab Emirates ( 36\%). Almost half (48\%) of all male Indian physicians from one study were smoking. For current smokers by gender, the highest smoking prevalence rates were $61 \%$ among male physicians in China and $34 \%$ among female physicians in Italy. A 
survey among Japanese physicians indicated that smoking prevalence among males in 2004 was $21.5 \%$, which was significantly lower than found in 2000 (27.1\%). Smoking prevalence among females in 2004 was $5.4 \%$ which was not significantly different from that in 2000 (6.8\%). ${ }^{11}$ A recent study from Alexandria (Egypt) observed that approximately $50 \%$ of physicians smoke. ${ }^{12}$ In Jordan's largest tertiary care hospital, $44 \%$ of interns and $75 \%$ of the emergency departments physicians indulge in smoking. ${ }^{13}$ Another study among physicians practicing in Istanbul ,Turkey reported that a smoking rate of $16 \%$ (14). A Polish study among pulmonary physicians observed a smoking rate of $10.1 \%$ ( $9 \%$ in women and , $13 \%$ in men). ${ }^{15}$ With 360 million smokers, China has more cigarette consumers than any other country-a smoking prevalence of $31 \%$ among the general population. Physicians in China are blamed as engines of nationwide tobacco-induced suffering. In a 2004 clustered randomized survey of 3552 hospital-based physicians from six Chinese cities, smoking prevalence was $23 \%$ among all Chinese physicians, $41 \%$ for men and $1 \%$ for women. ${ }^{16} \mathrm{~A}$ survey among 347 physicians from Wuhan, Hubei province in China observed that $58 \%$ of the male physicians and $18.8 \%$ of the female physicians were current cigarette smokers; $54.4 \%$ of the male and $70.4 \%$ of the female physicians often or always provided smoking counseling for patients. ${ }^{17}$ Do as I say, not as I do, seem to be the Chinese physician's advice for smokers!

A systematic review in 2006 of literature describing the prevalence and association of tobacco smoking among dentists in 15 countries observed that among all medical professionals, dentists have one of the lowest smoking rates. ${ }^{18}$ The prevalence of smoking has also declined in many countries during recent years. The lowest rates were documented in the United States (USA), Thailand, Finland, Australia, and Canada. However, in Italy and Jordan the dentists appear to be smoking at fairly high rates.

It is pertinent to accept that although a decline in physician smoking rates has been observed in some developed countries, the nexus between the physician and cigarette still continues. The findings are noteworthy because physicians are ambassadors of promoting issues related to health, and smokers among them are significantly less likely than their nonsmoking counterparts to advise their patients to quit smoking. Discussion of why physicians in some countries smoke at higher rates than others is beyond the scope of this article. The unholy alliance between the physicians and tobacco need to be broken for the betterment of humanity.

\section{Counsel the physician first}

"Doctors are just the same as lawyers; the only difference is that lawyers merely rob you, whereas doctors rob you and kill you, too"

\section{- Anton Chekhov, Ivanov-}

It is a paradox that the Great Russian physician, short-story writer and playwright were criticizing his own tribe. Did the luminary refer to the physicians who were smokers, and spreading the message of death in the society due to their misdeeds? Information about physician's health and health practices is sparse and scattered. However, available data indicate that smoking is a serious problem among physicians, and its ramifications are detrimental to the community. Doctors are generally viewed as exemplars by the community and patients, and have important roles in helping smokers quit. Physician's with better personal health habits and more positive attitude toward counseling counsel a broader range of patients and counsel more aggressively. ${ }^{19}$ Smokers are receptive to quit advice from physicians, but less likely to ask other health professionals such as pharmacists and dentists. ${ }^{20}$ Studies among medical professionals have reported that the following five variables were significantly associated with their smoking cessation counseling frequency. ${ }^{17}$

1. Their smoking status

2. Perceived success in the past counseling

3. Perceived influence

4. Perceived exemplary role

5. Perceived responsibility

Why is the rate of smoking high in the medical profession? Although not commonly recognized or discussed, physicians are people. If anything sets the physician apart from others, it is the special pressures and responsibilities that are intrinsic to the medical profession. Table-I outlines several difficult areas that 
Table-I

Factors that contribute to excessive mental stress on physicians

1. The need to deal with suffering and sometimes inflict suffering.

2. The need to allay patients fears.

3. The privilege of dealing with private aspects of a patient's body and life.

4. The frequent presence of death.

5. The need to handle 'unrealistic demands' of patients.

6. The expectation of perfection (no mistake allowed) that society demands.

7. The threat of physical harm and certain features of peer review.

8. Decreased autonomy.

9. Malpractice suits.

10. Increased competition due to more doctors being trained.

11. The emergence of greater role for other health professionals.

12. Decreased financial rewards.

have contributed to excessive mental stress on physicians. ${ }^{10,21,22,23}$ A positive response to these demands may well determine a physician's ability to assure high-quality patient and personal care. However, stress is not always the reason for smoking. In China, reasons for smoking among physicians varied from it being a social lubricant, a habit, stress reliever, and even a social status symbol. ${ }^{17}$ It is high time that the physicians who smoke, realize the harm they cause on themselves, and the community as a whole, and not rest until they have successfully kicked the habit. Indeed, the physicians office and hospital should be a model of non-smoking behavior. Education on smoking-cessation techniques need to be increased among physicians. Sharpening of counseling skills and a more humane approach towards patients can go a long way in pursuing patients quit smoking. Training in tobacco cessation counseling is deficient in medical schools even in developed countries such as the United States of America. ${ }^{24}$ It is imperative that smoking cessation techniques and tobacco-related issues are included in the medical school curricula,so that the future doctors are well prepared to effectively guide their nicotine-dependent patients to stop smoking. Tobacco dependence is a chronic relapsing disease that needs continuous treatment. Patient education, behavioral support, face-to-face counseling by physicians and pharmacotherapy can go a long way in achieving complete nicotine independence. Effective drugs that are often used to treat tobacco dependence are: Nicotine replacement therapy(NRT), Bupropion (150-mg sustained release tablets), and Varenicline (Chantix). ${ }^{25}$

\section{In summary}

Cigarette smoking, a modern peril, is one of the greatest threats to human health. However, the smoking prevalence is still high among the general public in most parts of the world, especially developing countries. Physicians have an important responsibility to convince their patients not to smoke, as they are generally viewed as exemplars by the community and patients. Unfortunately, the rate of smoking in the medical profession in some developed countries and newly-developing countries is still high. In view of the staggering cost of smoking in terms of human lives, physician's should not rest until they have successfully kicked the habit. Tobacco-related issues are to be included in the medical school curricula as medical students represent primary target for tobaccoprevention programs.

\section{References}

1. WHO Report on Global Tobacco Epidemic ,2008, Available on: http://www.who.int/tobacco/mpower/ mpower_report_full_2008. Accessed on 12 January 2009 . 
2. Jha P, Chaloupka FJ, Corrao M ,Jacob B. 2006.Reducing the burden of smoking world-wide: effectiveness of interventions and their coverage. Drug Alcohol Rev.25 (6):597-609.

3. Weglicki LS, Templin T,Hammad A,Jamil H, Abou Mediene S, Farrouk M, Rice VH.2007. Tobacco use among high school students: do Arab Americans differ? Ethn Dis.17: 22-24.

4. Burns DM. Nicotine addiction. Braunwald E, Fauci AS, Kasper DL, Hauser SL, Longo DL,Jameson JL,editors.2001. Harrisons Principles of Internal Medicine,vol2,15 ${ }^{\text {th }}$ edition, Mc Graw Hill Company: 2574-2577.

5. Becquemin MH, Bertholon JF, Attouli M, Roy F, Roy M, Dautzenberg B .2008 . Particle size in water pipe smoke. Rev Mal Respir. 25( 7 ) :839-846.

6. US Department of Health and Human Services. “ The health consequences of involuntary exposure to tobacco smoke: A report of the Surgeon General. June 27,2006.Available on: http://www.surgeongeneral. gov/library/secondhandsmoke Accessed on $12^{\text {th }}$ January 2009 .

7. Mathew BC, Daniel RS ,Bordom J. September 2008. Quit smoking and run for your life. Libyan J Med . 3 (3) .AOP: 090110.Available on : www.ljm.org.ly .Accessed on $12^{\text {th }}$ January 2009 .

8. Gardner MN, Brandt AM.2006. The doctors choice is Americas choice:the physician in US cigarette advertisements, 1930-1953.Am J Public Health. 96:222-232 .

9. Warner KE.1991.Tobacco industry scientific advisors: serving society or selling cigarettes? Am $J$ Public Health.81:839-842.

10. Smith DR, Leggat PA.2007. An intenational review of tobacco smoking in the medical profession : 19742004. BMC Public Health.7 :115. Available on : www.biomedcentral.com/1471-2458/7/115. Accessed on $12^{\text {th }}$ January 2009 .

11. Kaneita Y, Sakurai H, Tsuchiya T, Ohida T.2008. Changes in smoking prevalence and attitudes among Japanese physicians between 2000 and 2004 . Public Health. 122(9) : 882- 890 .

12. Sabra AA. 2007.Smoking attitudes, behaviours and risk perceptions among primary health care personnel in urban family medicine centers in Alexandria.J Eygpt Public Health Assoc. 82 (1-2):4364 .
13. El-Khushman HM , Sharara AM, Al-Laham YM, Hijazi MA.2008. Cigarette smoking among health care workers at King Hussain Medical Center.J Hosp Med . 3 ( 3):281-284.

14. Uysal MA, Dilman N, Karasulu L, Demir T.2007. Smoking habits among physicians in Istanbul and their attitudes regarding anti-smoking legislation. Tuberk Toraks. 55 (4) : 350- 355.

15. Korzybski D, Bilska A, Skrzypczynska E, Gorecka D. 2008. Smoking habits among Polish pulmonary physicians. Pnuumonol Alergol Pol. 76( 3): 142-147.

16. Jiang Y, Ong MK, Tong EK, Yang Y, Nan Y, Gan Q, $\mathrm{Hu}$ TW.2007. Chinese physicians and their smoking knowledge, attitudes and practices. Am J Prev Med.33(1): 15-22.

17. Li HZ, Sun W, Cheng F, Wang X , Liu W, Wang A. 2008. Cigarette smoking status and smoking cessation counseling of Chinese physicians in Wuhan, Hubei province. Asia Pacfic J Public Health .20(3) : 183-192.

18. Smith DR, Leggat PA.2006. A comparision of tobacco smoking among dentists in 15 countries. Int Dent J .56(5) :283-288.

19. Pipe A, Sorenson M, Reid R.2009.Physician smoking status, attitudes toward smoking, and cessation advice to patients: An international survey. Patient Educ Couns.74(1):118-123 .

20. Brewster JM , Victor JC, Ashley MJ. 2007. Views of Ontarians about health professional's cessation advice. Can J Public Health.98 (5): 395-399.

21. McCue JD.1982. The effects of stress on physicians in their medical practice. $N$ Engl J Med . 306:458463.

22. Hilfiker D.1984. Facing our mistakes. N Engl J Med . 310:118-122

23. Mawardi BH.1979. Satisfactions, dissatisfactions and causes of stress in medical practice.JAMA . 241:1483-1486.

24. Schkrohowsky JG, Kalasan B, Alberg AJ. 2007. Tobacco awareness in three U.S. medical schools. $J$ Addict Dis.26 (3): 101-106.

25. Corrozzi L, Pistelli F, Viegi G.2008. Pharmacotherapy for smoking cessation. Ther Adv Respir Dis .2(5) : 301-317. 